\title{
Effects of Solidification, Rotary Swaging and Recrystallization on the Microstructure, Crystallographic Orientation and Electrochemical Behavior of an Al-4.5 wt.\% Cu Alloy
}

\author{
J.C. Lourenço ${ }^{1, *}$, L.P. Souza ${ }^{1}$, G. Silva ${ }^{2}$, P.A. Suzuki ${ }^{1}$, A.L.M. Robin ${ }^{1}$, C.A. Nunes ${ }^{1}$, C.R. Tomachuk ${ }^{1}$ \\ ${ }^{1}$ Universidade de São Paulo, Escola de Engenharia de Lorena - EEL/USP, Pólo-Urbo Industrial, \\ Gleba AI-6, s/n, Lorena, SP, Brazil \\ ${ }^{2}$ Universidade Federal de Itajubá, Itajubá, Minas Gerais, Brazil. \\ "E-mail: julio.lourenco@usp.br
}

Received: 23 February 2021 / Accepted: 7 July 2021 / Published: 10 September 2021

\begin{abstract}
The evolution of the microstructure and grain orientation of metallic alloys during plastic deformation and recrystallization is of particular interest because these characteristics are known to strongly affect their mechanical properties and corrosion resistance. In this work, the hypoeutectic Al-4.5 wt.\% Cu alloy was produced under conventional and vertical upward unidirectional solidification, followed by rotary swaging with $54 \%, 76 \%$ and $91 \%$ degrees of deformation and recrystallization treatment at $350{ }^{\circ} \mathrm{C}$ for $60 \mathrm{~min}$. The microstructure of the as-cast alloy obtained by conventional solidification presented an equiaxed morphology, whereas that obtained by directional solidification was columnar. Rotary swaging led to gradual grain elongation, a decrease in interdendritic arm spacing and eutectic microsegregation. Recrystallization treatment changed the microstructure to an equiaxed morphology. The as-cast alloy obtained by conventional and unidirectional solidification routes presented the (111) and (200) preferred orientations, respectively. These preferred orientations gradually disappeared with plastic forming by rotary swaging, which was changed to the (220) preferred orientation in both cases as the deformation increased. A randomly oriented grain microstructure was obtained after recrystallization treatment. Under conventional solidification conditions, the as-cast sample exhibited better corrosion resistance. On the other hand, in the vertical upward unidirectional solidification condition, the deformed $91 \%$ recrystallized sample presented nobler behavior, while the as-cast sample presented lower corrosion resistance. Higher reductions promoted a reduction in the corrosion resistance of both solidification conditions. Changes in the crystallographic orientation promoted differences in the corrosion resistance.
\end{abstract}

Keywords: Al-Cu alloy, solidification, swaging, microstructure, texture

\section{$\underline{\text { FULL TEXT }}$}

(C) 2021 The Authors. Published by ESG (www.electrochemsci.org). This article is an open access article distributed under the terms and conditions of the Creative Commons Attribution license (http://creativecommons.org/licenses/by/4.0/). 